\title{
Use of a Home-Based Manual as Part of a Pulmonary Rehabilitation Program
}

\author{
Yves de Souza PT MSc, Kenia Maynard da Silva PT PhD, Diego Condesso PT, \\ Bianca Figueira PT, Arnaldo J Noronha Filho MD, Rogério Rufino MD PhD, \\ Rik Gosselink PT PhD, and Cláudia H da Costa MD PhD
}

\begin{abstract}
BACKGROUND: Pulmonary rehabilitation programs improve exercise capacity and quality of life in patients with COPD. Domiciliary strategies to maintain these benefits have been proposed. OBJECTIVE: This study aimed to determine whether a rehabilitation manual would facilitate the maintenance of the benefits acquired during out-patient pulmonary rehabilitation. METHODS: Fifty subjects with stable COPD were included (26 women and 24 men). All the subjects were evaluated during screening and after $12 \mathrm{wk}$ of out-patient rehabilitation, and then were randomly divided into 2 groups, with one group that received the rehabilitation manual for home use (manual group) and the other group only received verbal recommendations (control group). At this point, the 2 groups were similar. After 12 wk at home, both groups were evaluated a third time. All evaluations included a 6-min walk test (6MWT), 6-min step test, COPD Assessment Test, and measurement of dyspnea by using the modified Medical Research Council dyspnea scale. RESULTS: When comparing the results of the 6MWT and 6-min step test done at out-patient discharge and after $12 \mathrm{wk}$ at home, the manual group presented no differences $(6 \mathrm{MWT}, 0 \pm 25 \mathrm{~m}$; 6-min step test, $1 \pm 32$ steps), whereas the control subjects lost part of the gain obtained during rehabilitation (6MWT $-46 \pm 36 \mathrm{~m}$; 6-min step test $-39 \pm 33$ steps). There was a significant difference between the groups $(P<.05)$. When comparing the same time points, the change in the COPD Assessment Test score was $-1 \pm 1$ for the manual group and $1 \pm 2$ for the control group $(P=.01)$. For the modified Medical Research Council dyspnea scale, the change in score was $0 \pm 1$ for the manual group and $1 \pm 1$ for the control group $(P=.01)$. CONCLUSIONS: The use of a simple, well-illustrated manual facilitated the maintenance of the benefits acquired in out-patient pulmonary rehabilitation over a period of 3 months after study termination. Key words: COPD; pulmonary rehabilitation; breathing exercises; home-based rehabilitation; exercise capacity; domiciliary strategies. [Respir Care 2018;63(12):1485-1491. (c) 2018 Daedalus Enterprises]
\end{abstract}

\section{Introduction}

COPD is a major public health problem that is preventable and treatable. ${ }^{1}$ COPD is defined as bronchial obstruc-

\footnotetext{
Mr de Souza and Dr da Silva are affiliated with the Department of Physical Therapy, Veiga de Almeida University, Rio de Janeiro, Rio de Janeiro, Brazil. Mr de Souza, Dr da Silva, and Dr da Costa are affiliated with the Department of Pulmonary Medicine, State University of Rio de Janeiro, Rio de Janeiro, Brazil. Mr Condesso, Ms Figueira, Dr Noronha Filho, and Dr Rufino are affiliated with the Department of Pulmonary Medicine, State University of Rio de Janeiro, Rio de Janeiro, Brazil. Dr Gosselink is affiliated with the Department of Rehabilitation Sciences, Katholieke Universiteit Leuven, Leuven, Belgium.
}

tion, partially reversible, with the deterioration of lung function and, in most cases, is accompanied by significant systemic consequences, such as loss of muscle mass, exercise intolerance, dyspnea, and depression. ${ }^{2-4}$ Both pharmacologic and non-pharmacologic treatments are extremely important. Pulmonary rehabilitation is considered

\footnotetext{
Funding was provided by Fundação de Amparo à Pesquisa do Estado do Rio de Janeiro.

The authors have disclosed no conflicts of interest.

Supplementary material related to this paper is available at http:// www.rcjournal.com.
} 
a highly effective treatment of COPD ${ }^{5}$ and should be offered to all patients with moderate, severe, and very severe disease, as recommended in international guidelines. ${ }^{1}$

Pulmonary rehabilitation, integrated into individualized patient treatment, is designed to reduce symptoms, optimize functional status, increase adherence to treatment, and reduce health-care costs by stabilizing or reversing systemic manifestations of the disease. ${ }^{6}$ Most pulmonary rehabilitation programs include components for assessment, exercise training, educational sessions, and psychosocial intervention. ${ }^{7-9}$

Home pulmonary rehabilitation programs that last several weeks have been successful and manage to increase the exercise capacity and quality of life in patients with COPD. ${ }^{5}$ The effects of training, depending on the intensity and duration of the home rehabilitation program, can be maintained for 10 months ${ }^{10}$ or $1 \mathrm{y}^{11}$ after the cessation of exercise training. The importance of, and need for, appropriate strategies for maintaining gains has been recognized. As a result, several maintenance programs have been developed with different therapeutic interventions, structures, and design. ${ }^{12,13}$

Home rehabilitation is an excellent strategy to reduce the symptoms of patients with COPD and improves exercise capacity and quality of life. ${ }^{14}$ Both physical and functional benefits of pulmonary rehabilitation are maintained after the out-patient program when patients continue exercise training with a home program by using monthly calls as a strategy. ${ }^{11}$ With a small modification, a study that used walking, based on the 6MWT values as a guideline, showed good results in 6MWT and Chronic Respiratory Disease Questionnaire scores in subjects with moderate COPD when using weekly calls to encourage them. ${ }^{10}$

The American Thoracic Society/European Respiratory Society document ${ }^{5}$ on pulmonary rehabilitation propose strategies to facilitate the change of behavior of patients after rehabilitation, such as the use of pedometers and accelerometers, a cycle ergometer, and free hikes based on the 6MWT distance. However, some strategies are not easily accessible because of the high cost, such as telerehabilitation and self-management tools, such as accelerometers and pedometers. ${ }^{5}$ Thus, it was hypothesized that an easy-to-understand manual could be a low-cost tool and would be used by patients at home without the need to leave the comfort of their environment. This study aimed to investigate whether a rehabilitation manual prepared by

Correspondence: Yves de Souza PT MSc, Estrada Uniao e Industria, 13970/102 - Itaipava, Petropolis/RJ, Brazil, 25740-365. E-mail: souzayr@gmail.com.

DOI: $10.4187 /$ respcare. 05656

\section{QUICK LOOK}

\section{Current knowledge}

Pulmonary rehabilitation is the main physical intervention in patients with COPD as well as in other chronic lung diseases. Domiciliary strategies have been developed to help patients maintain the benefits achieved in outpatient rehabilitation.

\section{What this paper contributes to our knowledge}

An easy-to-use manual was shown to be able to maintain the gains in exercise capacity obtained during the out-patient period after 3 months of home monitoring. The protocol was simple and inexpensive, and could be replicated at any rehabilitation center.

our team could facilitate the maintenance of the benefits acquired during out-patient pulmonary rehabilitation.

\section{Methods}

Patients with stable COPD based on the GOLD (Global Initiative for Chronic Obstructive Lung Disease) criteria ${ }^{15}$ were followed up at the pulmonology clinic of the State University of Rio de Janeiro between December 2013 and August 2015. They received pharmacologic treatment according to the severity of the disease. The local ethics committee approved this randomized clinical trial, and all the subjects signed an informed consent form before performing scheduled procedures. The following inclusion criteria were considered: $>40$ y old, diagnosis of COPD, smoking history of $>20$ pack-years, having stopped smoking for at least 3 months before selection.

The exclusion criteria were the following: patients with other respiratory diseases, a diagnosis of alpha-1 antitrypsin deficiency, history of respiratory atopy, respiratory infections and/or exacerbations in the previous $30 \mathrm{~d}$, musculoskeletal disease that could compromise ambulation, uncontrolled comorbidity (hypertension with blood pressure $>180 / 110 \mathrm{~mm} \mathrm{Hg}$ or diabetes mellitus with symptoms of hypoglycemia), diagnosis of cognitive impairment that made it difficult to interpret the questions in the questionnaires or that compromised the use of a home rehabilitation manual, or patients who reported usually performing regular physical activities or who had already participated in a physical therapy program for the treatment of COPD. We assumed regular physical activities when the subject reported performing $\geq 90$ min of physical activities per week.

All the subjects were evaluated at 3 time points (Fig. 1) by the 6MWT, 6-min step test, and COPD Assessment 


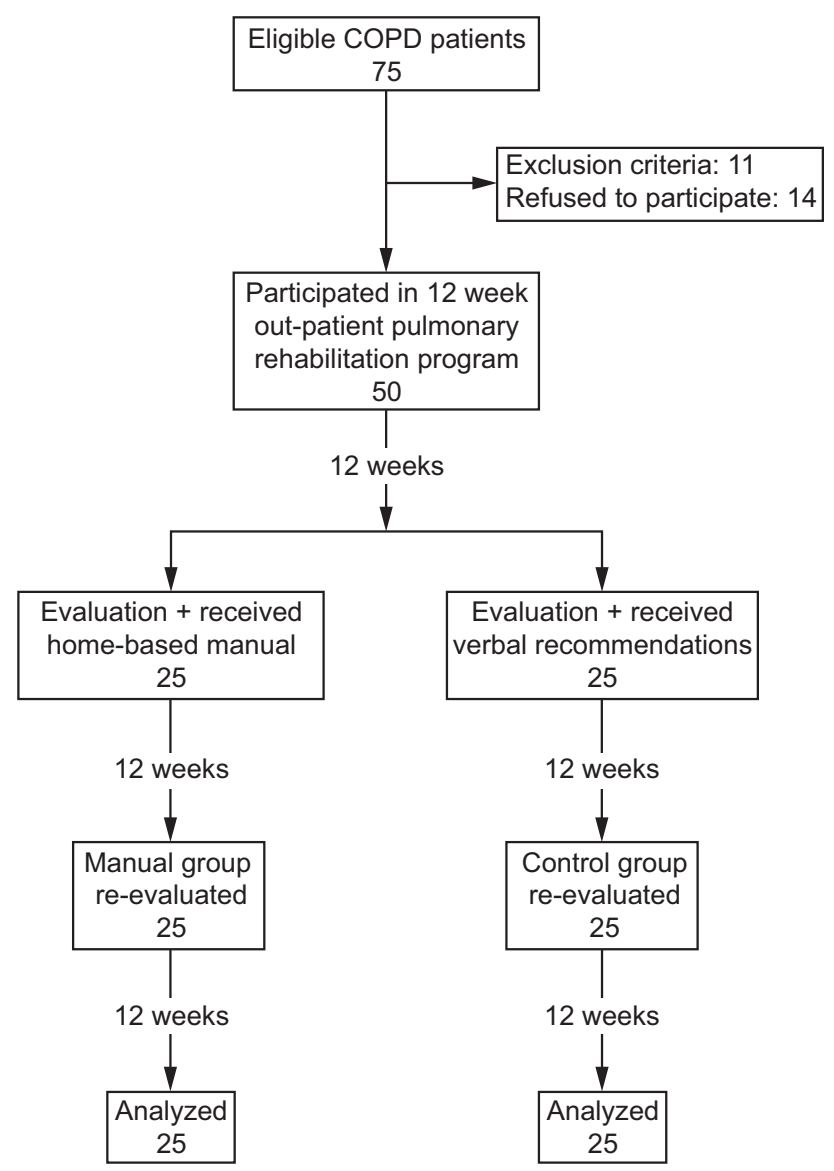

Fig. 1. Flow chart. Evaluations included the 6-min walk test, 6 -min step test, COPD Assessment Test, and modified Medical Research Council scale.

Test. ${ }^{16}$ Dyspnea was measured by the modified scale of the mMRC, ${ }^{17}$ and all the subjects also underwent spirometry testing with a bronchodilator test at each of the 3 stages. The 6MWT was performed according to the guidelines of the American Thoracic Society ${ }^{18}$ and the 6-min step test by following the standard of the latest study that compared the behavior of the heart rate between the 6MWT and 6-min step test, ${ }^{19}$ with both being held in the same morning. A 40-m-long corridor, every meter marked, was used to perform the 6MWT. The subjects were instructed to walk quickly but not run for 6 min.

The 6-min step test was done by using a single step, $16.5 \mathrm{~cm}$ high, $65 \mathrm{~cm}$ wide, and $30 \mathrm{~cm}$ deep. The subjects were instructed to walk up and down this step at their own pace, but without stopping. The number of ascents and descents was recorded by using a pedometer (New Balance VIA Step model New Balance Athletics, Inc. CA/USA). Before and after the tests, vital signs were assessed as well as dyspnea, measured by using the Borg scale..$^{20}$ Oxygen saturation was measured by using a Nonin Medical pulse oximeter (Onyx Vantage, model 9590 Nonin Medical, Inc. Plymouth, Minnesota/USA). Each test was replicated twice with an interval of $30 \mathrm{~min}$ in between; the best value was chosen for further analysis. Spirometric tests were performed by using a Vitatrace machine (Codax Ltda. Brazil) by following the standards of the American Thoracic Society, ${ }^{21}$ and all the subjects performed a bronchodilator test with $400 \mu \mathrm{g}$ of salbutamol. The Knudson reference equations were used. ${ }^{22}$ After the first evaluation, the subjects began a low-intensity pulmonary rehabilitation program in the out-patient clinic. The rehabilitation lasted for 12 weeks, with 2 supervised 45-min sessions per week, which comprised a sequence of respiratory exercises, upper- and lower-limb exercises, and step training (online supplement 1 [see the supplementary materials at http:// www.rcjournal.com]).

After 12 weeks, subjects were evaluated by using the same tests performed at the first evaluation and randomized by using the random site http://www.sorteador.com.br (Accessed April 21, 2014), into 2 groups. Only the principal investigator (YS) was informed of the group allocation. The group that received oral information about performing the exercises learned during the program served as the control group. The subjects in the second group, the manual group, received the manual and were instructed to use it daily. The subjects in both groups were told that they would be re-evaluated after 12 weeks. The manual (see the supplementary materials at http://www.rcjournal.com) consists of color pages, with each color representing a group of activities. Moreover, the illustrations are self-explanatory, with no need to use the guiding text to understand the exercises. Nevertheless, the text describes each figure in a simple exercise and the number of repetitions, which is always the same at each stage, thereby avoiding confusion and exaggerations in making some movements.

The manual has the same program as the out-patient rehabilitation, and the 20 repetitions of each exercise were used to facilitate the comprehension and memorizations of the exercise program. The subjects were instructed to selfmeasure by using the Borg scale after the exercises. When the subjects experienced strong breathlessness, they were instructed to use the breath control technique, to use inhalation medication or, in severe cases, to call their physician. After the home period, the subjects were again invited to repeat all assessments and examinations (third assessment), and we asked the subjects about their impression of how easy it was to use the manual. The study received ethical approval from the Hospital Universitário Pedro Ernesto (approval 255.321).

\section{Statistical Analysis}

The data were analyzed by using the GraphPad Prism 6.0 package (GraphPad Software, San Diego, California). The sample size calculation was performed by providing 
Table 1. General Characteristics of Subjects at First Assessment

\begin{tabular}{|c|c|c|c|}
\hline & $\begin{array}{c}\text { Manual } \\
(n=25)\end{array}$ & $\begin{array}{l}\text { No Manual } \\
(n=25)\end{array}$ & $P$ \\
\hline Sex, M/F & $10 / 15$ & $14 / 11$ & .25 \\
\hline Age, y & $67 \pm 10$ & $69 \pm 11$ & .56 \\
\hline Height, m & $1.61 \pm 0.10$ & $1.62 \pm 0.09$ & .83 \\
\hline Weight, kg & $66 \pm 12$ & $69 \pm 15$ & .46 \\
\hline BMI, $\mathrm{kg} / \mathrm{m}^{2}$ & $25 \pm 4$ & $26 \pm 5$ & .55 \\
\hline \multicolumn{4}{|l|}{ GOLD } \\
\hline A & 0 & 0 & \\
\hline B & 4 & 5 & \\
\hline $\mathrm{C}$ & 14 & 14 & \\
\hline $\mathrm{D}$ & 7 & 6 & \\
\hline $\mathrm{FEV}_{1}, \%$ pred & $40 \pm 14$ & $39 \pm 13$ & .77 \\
\hline FVC, $\%$ pred & $67 \pm 13$ & $68 \pm 14$ & .73 \\
\hline $\mathrm{FEV}_{1} / \mathrm{FVC}$, post-BD & $59 \pm 16$ & $57 \pm 15$ & .68 \\
\hline 6-min step test, no. steps & $246 \pm 99$ & $256 \pm 94$ & .70 \\
\hline $6 \mathrm{MWD}, \mathrm{m}$ & $358 \pm 83$ & $347 \pm 70$ & .59 \\
\hline $\mathrm{S}_{\mathrm{pO}_{2}}$ initial, $\%$ & $93 \pm 2$ & $93 \pm 3$ & .35 \\
\hline $\mathrm{S}_{\mathrm{pO}_{2}}$ final, $\%$ & $89 \pm 2$ & $88 \pm 3$ & .31 \\
\hline COPD Assessment Test & $23 \pm 5$ & $23 \pm 5$ & .97 \\
\hline $\mathrm{mMRC}$ & $4 \pm 1$ & $4 \pm 1$ & .16 \\
\hline \multicolumn{4}{|c|}{$\begin{array}{l}\text { BMI }=\text { body mass index } \\
\text { GOLD = Global Initiative for Chronic Obstructive Lung Disease } \\
\text { BD }=\text { Bronchodilator } \\
\text { 6MWD }=6 \text {-min walk distance } \\
\text { mMRC }=\text { modified Medical Research Council dyspnea scale. }\end{array}$} \\
\hline
\end{tabular}

the comparison of the means of the 2 groups by unpaired $t$ test with an alpha significance level of $5 \%$ and power of $95 \%$, which reached 46 individuals (23 per group). The results are presented as a mean \pm SD. The differences between assessments were compared by mixed 2-way repeated measures analysis of variance with post hoc tests at different time points, corrected for multiple testing with Bonferroni correction. A $P$ value of $<.05$ was considered statistically significant.

\section{Results}

We interviewed 75 patients before the evaluation, of whom 25 were excluded due to musculoskeletal disorders,${ }^{3}$ association with respiratory disease, ${ }^{4}$ cognitive impairment, ${ }^{2}$ and uncontrolled comorbidities, ${ }^{2}$ and 14 withdrew due to factors such as the distance of the residence or lack of interest in the program. From these patients, 50 subjects with stable COPD were evaluated and followed up until the end of the study; this was uneventful and without dropouts. The characteristics of the groups are presented in Table 1. All the subjects were symptomatic, as indicated by the COPD Assessment Test and mMRC, and participated in all assessments. There were no deaths, but there were 14 cases of mild-to-moderate exacerbation during the study period, most of them during the domiciliary period and in the control subjects.

During the interview performed at the follow-up, when asked about the frequency of the use the manual, all the subjects reported using the manual at least 4 times per week (4-6 d/week), but no subject reported using the manual every day. The subjects also reported that performing the exercise in a group during the out-patient program was more enjoyable than exercising alone at home. The control group tried to keep an active lifestyle, but all mentioned that symptoms were the principal limiting factor in keeping up with activities. After the domiciliary period (Fig. 2), the control subjects partially lost the exercise performance recently acquired by the rehabilitation program and showed worse symptom scores, whereas the manual group maintained the benefits achieved during the out-patient pulmonary rehabilitation.

This finding was confirmed when the differences among assessments were compared by mixed 2-way repeated measures analysis of variance with post hoc tests at different time points, corrected for multiple testing with Bonferroni correction (Table 2). Also, in the manual group, 2 of 25 subjects had exacerbations, whereas 16 of 25 control subjects had exacerbations $(P=.004)$. However, none of the participants were hospitalized. Dyspnea was also statistically lower in the manual group at the third assessment when analyzed by the mMRC scale when compared with the control group $(P=.033)$. The $\mathrm{FEV}_{1}$ was not statistically different between the subjects in the control and manual groups.

\section{Discussion}

This study evaluated a simple strategy to encourage patients with COPD, after discharge from out-patient pulmonary rehabilitation, through an easy-to-understand instrument. This manual provides features such as simple figures, different colors for different exercise modalities, and the same number of repetitions of each exercise. In the subjects' perceptions, the manual helped them to remember the order of the exercises, and the illustrations were easily understood. However, we used only one free-answer question to understand whether the manual was an easy-to-use instrument.

The results of this study showed that home-care strategies produced good results in the subjects with moderateto-severe COPD. When aiming to maintain the benefits of a short-term exercise training, Behnke et al $^{11}$ applied homebased walking training during 6 months in those with verysevere COPD after exacerbation and hospitalization. These investigators recruited 46 subjects hospitalized with COPD exacerbation, of whom, 30 finished all the procedures. Subjects randomized to the training group performed a 10-d training plan in the hospital and at discharge received 

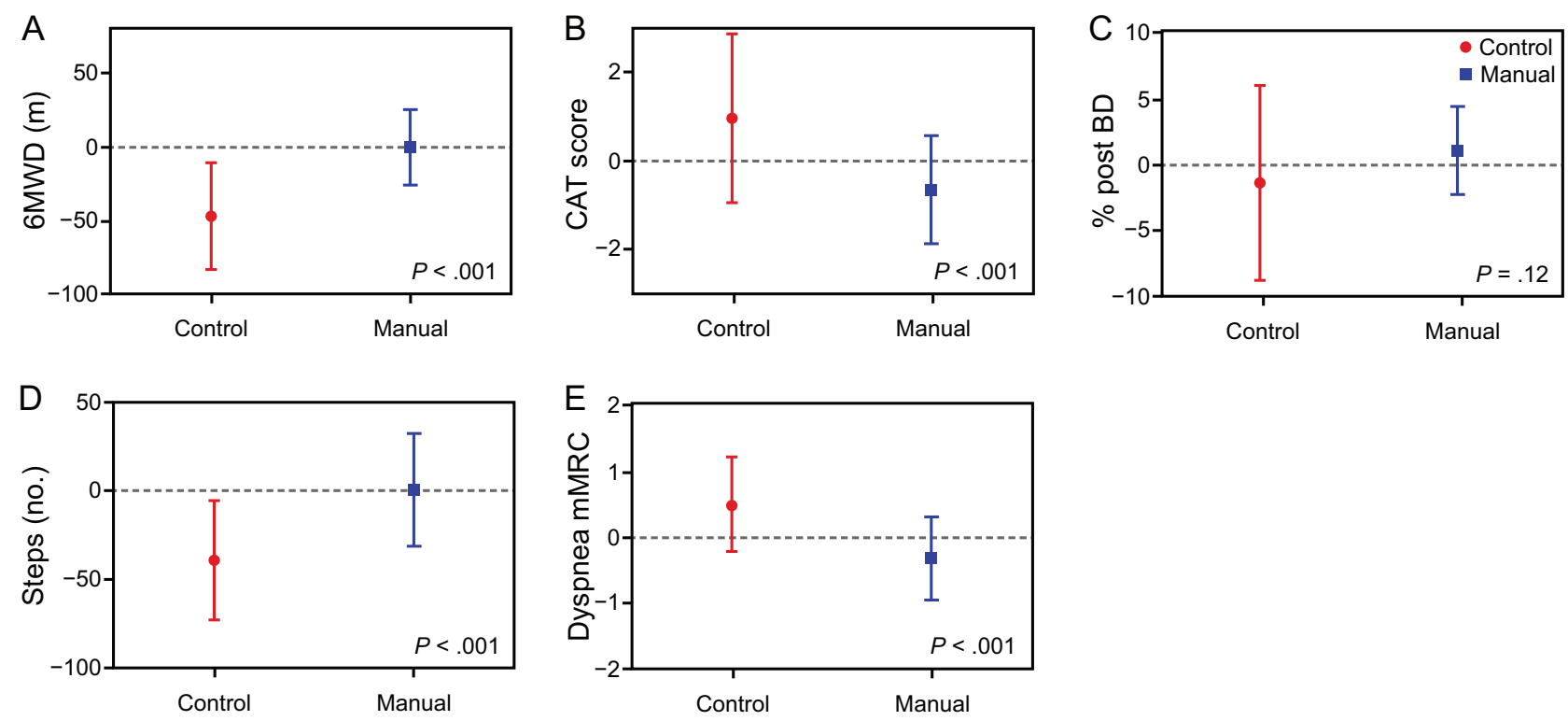

Fig. 2. Difference between the data acquired at the end of the out-patient rehabilitation program and the follow-up performed 3 months later. (A) 6-min walk distance; (B) COPD Assessment Test; (C) FEV ; $_{1}$ (D) 6-min step test; and (D) modified Medical Research Council scale.

Table 2. Comparison of Manual Group and the Control Group in 3 Assessments

\begin{tabular}{|c|c|c|c|c|c|c|c|c|c|c|}
\hline \multirow{2}{*}{ Parameters } & \multicolumn{3}{|c|}{ Manual } & \multicolumn{3}{|c|}{ Control } & \multirow{2}{*}{$\begin{array}{c}P, \text { Group by } \\
\text { Time Interaction } \\
\text { Effect }\end{array}$} & \multicolumn{3}{|c|}{$P$, Manual vs Control } \\
\hline & $\begin{array}{c}\text { First } \\
(n=25)\end{array}$ & $\begin{array}{l}\text { Second } \\
(n=25)\end{array}$ & $\begin{array}{c}\text { Third } \\
(n=25)\end{array}$ & $\begin{array}{c}\text { First } \\
(n=25)\end{array}$ & $\begin{array}{l}\text { Second } \\
(n=25)\end{array}$ & $\begin{array}{c}\text { Third } \\
(n=25)\end{array}$ & & First & Second & Third \\
\hline $\mathrm{FEV}_{1}, \%$ predicted & $40 \pm 14$ & $42 \pm 14$ & $43 \pm 14$ & $39 \pm 13$ & $42 \pm 15$ & $41 \pm 14$ & .38 & $>.99$ & $>.99$ & $>.99$ \\
\hline FVC, $\%$ predicted & $67 \pm 13$ & $67 \pm 17$ & $70 \pm 17$ & $68 \pm 14$ & $72 \pm 13$ & $72 \pm 13$ & .43 & $>.99$ & .75 & $>.99$ \\
\hline 6-min step test, no. steps & $246 \pm 99$ & $302 \pm 128$ & $304 \pm 124$ & $256 \pm 94$ & $315 \pm 120$ & $276 \pm 117$ & .001 & $>.99$ & $>.99$ & $>.99$ \\
\hline $6 \mathrm{MWD}, \mathrm{m}$ & $358 \pm 83$ & $420 \pm 93$ & $420 \pm 98$ & $347 \pm 70$ & $403 \pm 78$ & $357 \pm 85$ & $<.001$ & $>.99$ & $>.99$ & .041 \\
\hline COPD Assessment Test & $23 \pm 5$ & $18 \pm 5$ & $17 \pm 5$ & $23 \pm 5$ & $18 \pm 3$ & $19 \pm 2$ & .01 & $>.99$ & $>.99$ & .33 \\
\hline $\mathrm{mMRC}$ & $4 \pm 1$ & $2 \pm 1$ & $2 \pm 1$ & $4 \pm 1$ & $2 \pm 1$ & $3 \pm 1$ & $<.001$ & .51 & $>.99$ & .033 \\
\hline
\end{tabular}

6MWD $=6$-min walk distance

mMRC $=$ modified Medical Research Council dyspnea scale. $P$ value of post hoc between group comparisons of mixed 2-way analysis of variance repeated measures analysis at different time points with Bonferroni corrections.

a tailored instruction to practice walking at home. These subjects were visited every 2 weeks by investigators to check their activities during the first 3 months, and, afterward, the contacts were done by telephone. The gain obtained by this group during hospitalization was maintained after 6 months. The control group showed no significant changes in exercise performance.

Different from the work by Behnke et $\mathrm{al}^{11}$, in the present study, all the subjects performed rehabilitation for 3 months and, afterward, were randomized into 2 groups (with and without the manual). None of our subjects received any contact at home during the 3 months. Despite the differences, both studies were able to report the benefits of home-based training by using simple tools.

The manual succeeded in maintaining the gains in the exercise capacity obtained during the out-patient period after 3 months of home monitoring. The control group had a functional decline and presented 6MWT and 6-min step test scores similar to baseline at 3 months after discharge. When comparing the second and third assessments, the control subjects had a decrease in the 6-min walk distance of $46 \mathrm{~m}$ on average. This significant loss of exercise capacity in a few months could be explained, at least in part, because the subjects in the control group practiced less physical activity that resulted in the loss of exercise performance, whereas the manual group continued an exercise routine.

Furthermore, in this study, 6-min walk distance decreased more in the subjects who presented with exacerbations during the domiciliary period, most of them in the control group. It is known that exacerbations of COPD have shortand long-term clinical implications, and that one of these 
is a decrease of exercise capacity. ${ }^{23,24}$ Although lung function was not affected in the control group, symptom scores and exercise performance declined after the domiciliary period compared with the end of the rehabilitation program. This loss in exercise capacity acquired by the rehabilitation program had already been reported by du Moulin et al. ${ }^{10}$ These investigators performed a 3-week out-patient pulmonary rehabilitation and followed moderate COPD subjects for 6 months by using a maintenance program in their intervention group. ${ }^{10}$ The intervention was to instruct subjects to walk a distance equivalent to $125 \%$ of their last 6-min walk distance 3 times per day and to report this in a diary; the subjects were also contacted monthly by telephone. ${ }^{10}$

This study has some similarities with our study because they also included subjects of equivalent age and severity of disease and reported that training exercise at home is feasible and can maintain the effects of the pulmonary rehabilitation..$^{10}$ We agree that out-patient rehabilitation is important to increase exercise capacity and that strategies to maintain the benefits acquired in this program are essential for long-term success. Our study also evaluated the lung function of the participants by using spirometry. The spirometric data varied slightly in both groups, although these values were not statistically significant. However, a tendency toward an increase was identified, as was also demonstrated by du Moulin et al. ${ }^{10}$ In our study, the subjects were instructed to return after 3 months to test the capacity of the manual as a single strategy, and they did not receive any call during this period.

Holland et al compared an 8-week home-based training plan with pulmonary rehabilitation performed in an outpatient center. ${ }^{25}$ The investigators suggest that the homebased model could be equivalent to the center-based program. Our study aimed to investigate the maintenance of the effects achieved in a center-based rehabilitation program rather than to compare both modalities. ${ }^{25}$ Holland et al reported that approximately $10 \%$ of their subjects did not complete the 1-y follow-up, whereas, in our study, all the subjects completed the home-based period. This better adherence in our study might be related to the difficulty of access to the public health system in our country. When subjects are invited to participate in clinical trials and receive treatment, they do not easily give up their participation, especially when they perceive that there is a benefit to their quality of life. Moreover, the period of follow-up in our study was 3 months, whereas in the study by Holland et al, this was $1 \mathrm{y} .{ }^{25}$

Our protocol was simple and inexpensive, and could be replicated in any rehabilitation center. The proposed manual can assist the maintenance of pulmonary rehabilitation exercises. However, behavioral changes and the implementation of a healthier lifestyle based on physical activity should be pursued through other resources. We believe that this tool can assist in this change, but it should not be seen as the solution to the maintenance of pulmonary rehabilitation gains. In our trial, we did not use telephone calls or other means to contact the subjects to test the manual, but we trust that this method can be powerful to reinforce the necessity of keeping up with the exercises.

\section{Conclusions}

In this study, we showed that a home-based rehabilitation manual, which included respiratory exercises, upperand lower-limb exercises, step training, and strategies to control dyspnea, was effective in maintaining the benefits acquired during an out-patient rehabilitation program. This manual brings together features that facilitate its use among patients with COPD.

\section{REFERENCES}

1. Vestbo J, Hurd SS, Agustí AG, Jones PW, Vogelmeier C, Anzueto A, et al. Global strategy for the diagnosis, management, and prevention of chronic obstructive pulmonary disease: GOLD executive summary. Am J Respir Crit Care Med 2013;187(4):347-365.

2. Celli BR, MacNee W, ATS/ERS Task Force. Standards for the diagnosis and treatment of patients with COPD: a summary of the ATS/ERS position paper. Eur Respir J 2004;23(6):932-946.

3. van Eeden SF, Hogg JC. The response of human bone marrow to chronic cigarette smoking. Eur Respir J 2000;15(5):915-921.

4. Lacasse Y, Goldstein R, Lasserson TJ, Martin S. Pulmonary rehabilitation for chronic obstructive pulmonary disease. Cochrane Database Syst Rev 2006;(4):CD003793.

5. Spruit MA, Singh SJ, Garvey C, ZuWallack R, Nici L, Rochester C, et al; ATS/ERS Task Force on Pulmonary Rehabilitation. An official American Thoracic Society/European Respiratory Society statement: key concepts and advances in pulmonary rehabilitation. Am J Respir Crit Care Med 2013;188(8):e13-64.

6. Donaldson AV, Maddocks M, Martolini D, Polkey MI, Man WD. Muscle function in COPD: a complex interplay. Int J Chron Obstruct Pulmon Dis 2012;7:523-535.

7. Ries AL. Pulmonary rehabilitation: summary of an evidence-based guideline. Respir Care 2008;53(9):1203-1207.

8. Azarisman SM, Hadzri HM, Fauzi RA, Fauzi AM, Faizal MP, Roslina MA, Roslan H. Compliance to national guidelines on the management of chronic obstructive pulmonary disease in Malaysia: a single centre experience. Singapore Med J 2008;49(11):886-891; quiz 892-896.

9. Kaplan A. The COPD action plan. Can Fam Physician 2009;55(1): 58-59.

10. du Moulin M, Taube K, Wegscheider K, Behnke M, van den Bussche H. Home-based exercise training as maintenance after outpatient pulmonary rehabilitation. Respiration 2009;77(2):139-145.

11. Behnke M, Taube C, Kirsten D, Lehnigk B, Jörres RA, Magnussen H. Home-based exercise is capable of preserving hospital-based improvements in severe chronic obstructive pulmonary disease. Respir Med 2000;94(12):1184-1191.

12. Troosters T, Gosselink R, Decramer M. Short- and long-term effects of outpatient rehabilitation in patients with chronic obstructive pulmonary disease: a randomized trial. Am J Med 2000;109(3):207212.

13. Nici L. Can we make it last? Maintaining benefits achieved with pulmonary rehabilitation. Lung 2007;185(5):241-242. 
14. Liu XL, Tan JY, Wang T, Zhang Q, Zhang M, Yao LQ, Chen JX. Effectiveness of home-based pulmonary rehabilitation for patients with chronic obstructive pulmonary disease: a meta-analysis of randomized controlled trials. Rehabil Nurs 2014;39(1):36-59.

15. Vogelmeier CF, Criner GJ, Martinez FJ, Anzueto A, Barnes PJ, Bourbeau J, et al. Global strategy for the diagnosis, management, and prevention of chronic obstructive lung disease 2017 report: GOLD Executive Summary. Am J Respir Crit Care Med 2017;195(5):557582.

16. Baria MR, Shahgholi L, Sorenson EJ, Harper CJ, Lim KG, Karuka AH, et al. B-Mode Ultrasound Assessment of Diaphragm Structure and Function in Patients With COPD. Chest 2014;146(3):680-685.

17. Kovelis D, Segretti NO, Probst VS, Lareau SC, Brunetto AF, Pitta F. Validation of the Modified Pulmonary Functional Status and Dyspnea Questionnaire and the Medical Research Council scale for use in Brazilian patients with chronic obstructive pulmonary disease. J Bras Pneumol 2008;34(12):1008-1018.

18. ATS Committee on Proficiency Standards for Clinical Pulmonary Function Laboratories. ATS statement: guidelines for the six-minute walk test. Am J Respir Crit Care Med 2002;166(1):111-117.

19. da Costa CH, da Silva KM, Maiworm A, Raphael Y, Parnayba J, Da $\mathrm{Cal} \mathrm{M}$, et al. Can we use the 6-minute step test instead of the 6-minute walking test? An observational study. Physiotherapy 2017; 103(1):48-52.

20. Borg G. Perceived exertion as an indicator of somatic stress. Scand J Rehabil Med 1970;2(2):92-98.

21. Miller MR, Hankinson J, Brusasco V, Burgos F, Casaburi R, Coates A, et al; ATS/ERS Task Force. Standardisation of spirometry. Eur Respir J 2005;26(2):319-338.

22. Knudson RJ, Lebowitz MD, Holberg CJ, Burrows B. Changes in the normal maximal expiratory flow-volume curve with growth and aging. Am Rev Respir Dis 1983;127(6):725-734.

23. Qureshi H, Sharafkhaneh A, Hanania NA. Chronic obstructive pulmonary disease exacerbations: latest evidence and clinical implications. Ther Adv Chronic Dis 2014;5(5):212-227.

24. Garcia-Aymerich J, Lange P, Benet M, Schnohr P, Antó JM. Regular physical activity modifies smoking-related lung function decline and reduces risk of chronic obstructive pulmonary disease: a population-based cohort study. Am J Respir Crit Care Med 2007;175(5):458-463.

25. Holland AE, Mahal A, Hill CJ, Lee AL, Burge AT, Cox NS, et al. Home-based rehabilitation for COPD using minimal resources: a randomised, controlled equivalence trial. Thorax 2017;72(1):57-65.

This article is approved for Continuing Respiratory Care Education credit. For information and to obtain your CRCE

(free to AARC members) visit www.rcjournal.com 